
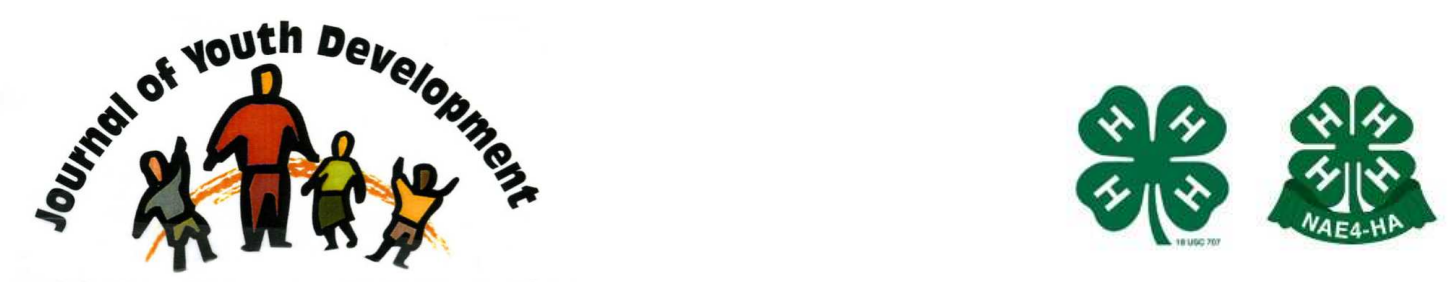

Bridging Research \& Practice

\title{
The Healing Species: \\ Animal-Assisted Character Education for Improving Student Behavior
}

Wanda J. Pearson

Tidwell \& Associates, Inc.

Columbia, SC

wpearson@grantmaster.org 


\title{
JOURNAL OF YOUTH DEVELOPMENT \\ bridging research and practice

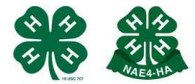

Bridging Research \& Practice

Volume 6, Number 1, Spring 2011

Article 110601PA001

\section{The Healing Species: Animal-Assisted Character Education for Improving Student Behavior}

Wanda J. Pearson

Tidwell \& Associates, Inc.

\begin{abstract}
The Healing Species program aims to reduce disruptive behaviors at school by increasing students' abilities to avoid conflict when possible and to resolve conflicts peaceably when they occur. The program's 11 lessons incorporate elements of behavior theory that postulate behavior follows belief. This study hypothesized that 5th and 6th grade students who completed the Healing Species curriculum would show fewer normative beliefs favoring aggression, greater empathy, and fewer disciplinary infractions, than a comparable group of students who did not receive the Healing Species program. Lessons included the participation of rescued dogs to emphasize compassion, empathy, responsibility, and forgiveness. Study results offered evidence of improved overall behavior and specific reductions in violence and aggression.
\end{abstract}

\section{Introduction}

Since the Columbine killings in 1999 elevated societal concerns about adolescent mental health, youth serving institutions have stepped up efforts to maintain safe, secure environments. Schools have been at the forefront of this movement, which has increased demand for programming to prevent school violence. The Healing Species program was developed to help pre-adolescent (ages 9-11) and adolescent youth (ages 12-15) acquire the knowledge and skills needed to disrupt cognitive-emotional circuits activating aggressive behaviors. The curriculum's 11 lessons incorporate the participation of rescued dogs to teach responsibility, compassion, empathy, and forgiveness to youth in school-based settings. The program aims to reduce interpersonal violence among students by reducing approval of aggression and increasing empathy.

A previous program evaluation found the Healing Species program appeared to reduce out-ofschool suspensions for violent behavior by $55 \%$, reduce retaliation aggression behavior by $66 \%$, and increase choice making using empathy by $42 \%$ (Sprinkle, 2008). Anecdotal reports from 
teachers and guidance counselors described significant improvement in students' abilities to manage conflict without violence and demonstrate empathetic attitudes and behavior. Thus, Healing Species appeared to meet schools' needs for violence prevention programming that works. A shortcoming of the previous study, however, was the lack of a comparison group. The present evaluation's quasi-experimental design included a comparison group whose outcomes provided added context in interpreting the evaluation findings.

The Healing Species character education program was developed 10 years ago following its founder's observation that the violent offenders she encountered as a criminal lawyer had common histories as perpetrators of animal abuse. In support of the founder's experience, a substantial body of literature has concluded that cruelty toward animals in childhood is a reliable indicator of conduct disorder in adolescents, a predictor of violent behavior in adulthood, and a marker for children experiencing abuse (Flynn, 1999; Miller \& Knutson, 1997).

On the other hand, animal cruelty may be symptomatic of underlying conditions that, if ameliorated, may eliminate a child's maladaptive behavior. In Ghosts from the Nursery: Tracing the Roots of Violence (Karr-Morse \& Wiley, 1997), the authors present overwhelming evidence that conduct disorder has its basis in early disruption, trauma, and abuse, making the case that much antisocial behavior is preventable or remediable. This finding is consistent with the literature on aggression which has shown differences in aggressive behavior appear to result from interactions among an individual's biological predisposition, physical environment, and social learning (Anderson et al., 2003; Berkowitz, 1993; Patterson, DeBaryshe, \& Ramsey, 1989).

Sentinel indicators of youth well-being are grim in the community and schools in which the Healing Species program was conducted. Over $80 \%$ of the students at the two schools in the study qualify for the free- or reduced-price lunch program, an indicator suggestive of poverty and concomitant stress. According to US Census Bureau estimates for 2007, the surrounding county's overall poverty rate of $23.2 \%$ exceeds the state poverty rate of $15 \%$ and is nearly double the national rate of $13 \%$. At $29.2 \%$, the poverty rate is higher still among Black or African Americans who comprise $63 \%$ of the county's population and $92 \%$ of the students served by the Healing Species program.

A substantial body of literature has documented the correlation between poverty and low academic achievement. The relationship was evident among the students in the study. While $70 \%$ of the elementary students tested met state standards for English/Language Arts in 2007, success rates in the other core domains of Mathematics, Science, and Social Studies were $63.6 \%, 41.7 \%$, and $58.3 \%$, respectively. The middle school students-grades 6, 7, \& 8missed the $70 \%$ mark in all four domains at all three grade levels.

Research examining the income-achievement gap has found significant cognitive deficits among children living in poverty (Farah, et al., 2006). Evans and Schamberg found childhood poverty negatively affected working memory in young adults, and the memory deficits may have been biological consequences of chronic stress (Evans \& Shamberg, 2009). Embry's findings on the effects of stress on youth brain development and behavior have informed the development of interventions to supplant the perceived rewards of aggression and other antisocial behaviors (Embry, 1996, 1999, 2004). In the absence of effective interventions, stress has shown to be a factor in youth aggression and violence. 
Before implementing the Healing Species program, the schools described problems with disruptive student behaviors. In the preceding school year, the rate of student referrals to the administrative office for disciplinary violations was $18.8 \%$. Incidents involving aggressive behavior among students (fighting, threats, intimidation, hitting, obscene gestures) were $11 \%$ of the 1,404 total violations by 5th and 6th grade students. Aggressive student behaviors towards teachers and other staff were $40 \%$ of the total. Offenses in this category included simple assault, threats, disrespect, and refusal to obey. Healing Species sought to reduce the incidences of aggression and violence by teaching the students prosocial strategies for managing stress and conflict.

The risk factors posed by academic difficulties and economic distress are exacerbated by the students' exposure to community violence. In 2007, the county's rate of violent crime (murder, rape, robbery, and aggravated assault) was 67.29 per 10,000 residents and has increased $8.9 \%$ since 2005. Dog fighting and other organized criminal activity also negatively impact children's socialization in the largely rural county. Exposure to community violence has been linked to children's increased risk for developmental deficits, behavioral problems, and academic failure (Haberman, 1994; Perry, 1999).

\section{Methods}

The study hypothesized that 5th and 6th grade students who completed the Healing Species curriculum would show fewer disciplinary infractions, fewer normative beliefs favoring aggression, and greater empathy than a comparable group of students who did not receive the Healing Species program. Based on the literature, the study expected improved behavior to follow a reduction in approval of aggression and an increase in empathy.

Behavior Hypothesis

$\mathrm{H}_{0}$ : $\quad$ Completing the Healing Species program will have no effect on or increase students' rate of incurring disciplinary infractions

$\mathrm{H}_{\mathrm{A}}$ : $\quad$ Completing the Healing Species Program will reduce the rate at which students incur disciplinary infractions

Aggression Hypothesis

$\mathrm{H}_{0}$ : $\quad$ Completing the Healing Species program will have no effect on or will increase students' normative beliefs favoring aggression

$\mathrm{H}_{\mathrm{A}}$ : $\quad$ Completing the Healing Species Program will reduce students' normative beliefs favoring aggression

Empathy Hypothesis

$\mathrm{H}_{0}$ : $\quad$ Completing the Healing Species Program will have no effect on or will decrease students' cognitive levels of empathy

$\mathrm{H}_{\mathrm{A}}$ : Completing the Healing Species Program will increase students' cognitive levels of empathy

The evaluation included one middle school serving grades 6-8 and one feeder elementary school, grades K-5. Due to small class sizes, all of the fifth and sixth graders at each school were invited to participate. The schools were selected based on their previous experience with the Healing Species program and their interest in helping the program to be rigorously evaluated. The schools were in a low-income urban district, and the student populations were $92 \%$ black or African American, in contrast to a previous study where the majority of 
participants were non-Hispanic white (Sprinkle, 2008). The study population's demographics are shown in Tables 1 and 2 below.

Table 1

Participant Demographics (Gender and Race by Grade)

\begin{tabular}{|c|c|c|c|c|c|c|c|}
\hline \multirow{2}{*}{ GENDER } & \multicolumn{3}{|c|}{$5^{\text {th }}$ Grade $(n=22)$} & \multicolumn{3}{|c|}{$6^{\text {th }}$ Grade $(n=179)$} & \multirow{2}{*}{ TOTAL } \\
\hline & Black & White & Other & Black & White & Other & \\
\hline Female & 12 & 1 & 1 & 86 & 18 & 2 & 120 \\
\hline Male & 5 & 3 & 0 & 51 & 21 & 1 & 81 \\
\hline TOTAL & 17 & 4 & 1 & 137 & 39 & 3 & 201 \\
\hline
\end{tabular}

Table 2

Participant Demographics by Study Group

\begin{tabular}{|c|c|c|c|c|c|}
\hline \multirow{2}{*}{\multicolumn{3}{|c|}{ RACE }} & \multicolumn{3}{|c|}{ GENDER } \\
\hline & & & \multirow{2}{*}{$\begin{array}{r}\text { Male } \\
24\end{array}$} & \multirow{2}{*}{$\begin{array}{r}\text { Female } \\
34\end{array}$} & \multirow{2}{*}{$\begin{array}{r}\text { Total } \\
58\end{array}$} \\
\hline \multirow{3}{*}{ Black } & \multirow{3}{*}{ Group } & Comparison & & & \\
\hline & & Treatment & 32 & 64 & 96 \\
\hline & & Total & 56 & 98 & 154 \\
\hline \multirow{3}{*}{ White } & \multirow{3}{*}{ Group } & Comparison & 11 & 3 & 14 \\
\hline & & Treatment & 13 & 16 & 29 \\
\hline & & Total & 24 & 19 & 43 \\
\hline \multirow{3}{*}{ Other } & \multirow{3}{*}{ Group } & Comparison & 1 & 0 & 1 \\
\hline & & Treatment & 0 & 3 & 3 \\
\hline & & TOTAL & 1 & 3 & 4 \\
\hline \multicolumn{3}{|c|}{ Full Group Total } & 81 & 120 & 201 \\
\hline
\end{tabular}

The project distributed 332 consent forms to parents/caregivers and 242 were returned for a response rate of $72.9 \%$. The initial study sample consisted of 32 fifth graders and 206 sixth graders. Attrition caused by internal student transfers and external family mobility reduced the final population to 201 students with matched pre- and post-tests.

\section{Measurement}

The measurement instruments used were the Normative Beliefs About Aggression Scale (NOBAGS; Huesmann \& Guerra, 1997; Huesmann, Guerra, Miller, \& Zelli, 1989), and the Index of Empathy for Children and Adolescents (IECA; Bryant, 1982). Both instruments were used in the previous evaluation of The Healing Species program (Sprinkle, 2008) and were carried forward to the current evaluation for consistency in assessing the program's impact. NOBAGS (alpha $=.86$ ) has been standardized and normed on urban student populations with demographics characteristics matching those of the students in the current evaluation's program and comparison groups (Huesmann \& Guerra, 1997). For the population included in this evaluation, the reliability of the instrument, as determined by Cronbach's alpha, was .81. The NOBAGS consists of 20 questions comprising a large scale, and two subscales.

The first subscale, questions 1-12, measures Retaliation Aggression (aggression in response to provocation). The second subscale consists of questions 13-20 and measures approval of General Aggression (no specific conditions). One large scale, Total Aggression, encompasses questions 1-20. Each question is scored on a 4-point scale, from $1=$ Really Wrong, to 
4=Perfectly OK. For each scale, lower scores indicate fewer normative beliefs about aggression. The scoring ranges for each scale are shown in the table below. Scores for each scale are calculated as the mean of the scores on each question on the scale that is answered by the respondent.

Table 3

Scale for Scoring Responses to NOBAGS

\begin{tabular}{|c|c|}
\hline SCALE & $\begin{array}{c}\text { SCORING } \\
\text { RANGE }\end{array}$ \\
\hline Retaliation Aggression & 12 to 48 \\
\hline General Aggression & 8 to 32 \\
\hline Total Aggression & 20 to 80 \\
\hline
\end{tabular}

The IECA (alpha $=.81$ ) was the subject of a validation study involving a population of socioeconomically diverse elementary and middle school students. Among the students participating in this study of the Healing Species project, the instrument's reliability was .907 as determined by Cronbach's alpha. The Index of Empathy for Children and Adolescents is designed as one large scale of 22 questions. The minimum score is 0 , and the maximum is 22 . The instrument has two versions with different response sets depending on the ages of the study population. The Yes/No format was used for this evaluation because of the number of participants who were 11 years old or younger. Higher scores indicate high levels of empathy, and low scores indicate low levels of empathy (Bryant, 1982).

To assess the impact of beliefs upon behavior, the study used student disciplinary data from the school district's database. The school district's disciplinary data consisted of a report of infractions by date and type. From the report, the study determined pre- and post-intervention incidences of disciplinary infractions for each student and the total number of infractions by date and type for the Program and Comparison groups.

\section{Design and Procedures}

The evaluation employed a quasi-experimental nonequivalent group design. Pure random assignment to the treatment or control group was not possible within the school setting without significant disruptions to existing pupil classroom assignments. Rather, intact classrooms were arbitrarily divided into two groups, Program and Comparison, at each grade level. The Program classrooms received the Healing Species program during fall semester of school year 2007-08. The Comparison group classrooms subsequently received the program in the following spring. The consenting students in both groups were administered the NOBAGS and IEAC instruments one week prior to the Program group's first Healing Species lesson. To minimize risks of data loss due to literacy problems or other reading comprehension difficulties, the instruments were administered by reading the questions aloud to the students.

During weeks two through twelve, the Program group completed the Healing Species curriculum, one lesson per week. The three instruments were re-administered to all participants in both groups in the week following the last Healing Species lesson for the fall semester. To measure student behavior, the study collected disciplinary data by student, date, and type of infraction for each semester of the 2007-08 school year. 
Healing Species' lessons are designed for presentation in order from 1 to 11 . For implementation fidelity, the program was presented during social studies class periods. Incorporating the program through a core subject enabled Healing Species to reach all fifth and sixth grade students, which helped to mitigate threats to internal validity from the lack of pure random assignment. Classrooms in the comparison group received the Healing Species lessons during the last 11 weeks of the spring semester to enable access for all students to the curriculum's potential benefits.

\section{Results}

Data analysis was conducted using SPSS Version 16.0. All significant values are reported at $p$ values corresponding to $* p<.05, * * p<.01$, or $* * * p<.001$. Two-tailed comparisons between observed values and test statistics were used because the study made no assumptions regarding the direction of change in beliefs or behavior for the Comparison group.

Data were first analyzed to determine if the two groups were indeed comparable despite the absence of true random assignment. The Levene test of homogeneity of variances was used to test for significant differences in the groups' pre-intervention scores on each measure. The results showed no significant selection bias $(p<.05)$. The results were consistent with the schools' inclusion model for pupil assignment. Each of the classrooms in the study was equally likely to have students whose unique intellectual, physical, emotional, or mental characteristics may have been expected to influence the students' scores on the pre- and post-tests.

Results for Normative Beliefs About Aggression (NOBAGS)

Paired-samples T-tests were conducted to assess the direction and magnitude of change in the students' pre- and post-test scores.

- Analysis of the Program group's mean scores on the measures of aggression revealed the theorized decline in approval of aggression occurred in one dimension, Retaliation Aggression. Overall, however, the changes in the group's mean scores between preand post-test did not achieve significance at the level $p=.05$.

Table 4

Paired Samples T-tests of NOBAGS Scores for Program Group

\begin{tabular}{|c|c|c|c|c|c|c|c|c|}
\hline \multirow{3}{*}{ NOBAGS Dimension } & \multicolumn{8}{|c|}{ Paired Differences } \\
\hline & \multirow[b]{2}{*}{ Mean } & \multirow{2}{*}{$\begin{array}{c}\text { Std. } \\
\text { Deviation }\end{array}$} & \multirow{2}{*}{$\begin{array}{l}\text { Std. } \\
\text { Error } \\
\text { Mean }\end{array}$} & \multicolumn{2}{|c|}{$\begin{array}{l}\text { 95\% Confidence } \\
\text { Interval of the } \\
\text { Difference }\end{array}$} & \multirow[b]{2}{*}{$\mathbf{t}$} & \multirow[b]{2}{*}{ df } & \multirow{2}{*}{$\begin{array}{c}\text { Sig. } \\
(2- \\
\text { tailed) }\end{array}$} \\
\hline & & & & Lower & Upper & & & \\
\hline $\begin{array}{l}\text { Total Aggression Pre-test } \\
\text { Total Aggression Post-test }\end{array}$ & .01694 & .43469 & .03842 & -.05909 & .09297 & .441 & 127 & .660 \\
\hline \begin{tabular}{|l} 
General Aggression Pre-test \\
General Aggression Post-test
\end{tabular} & .05999 & .48020 & .04244 & -.02400 & .14398 & 1.413 & 127 & .160 \\
\hline $\begin{array}{l}\text { Retaliation Aggression Pre-test } \\
\text { Retaliation Aggression Post-test }\end{array}$ & -.01095 & .55450 & .04901 & -.10793 & .08603 & -.223 & 127 & .824 \\
\hline
\end{tabular}

The Comparison group's mean scores on the NOBAGS instrument indicated stronger normative beliefs favoring aggression (Table 5). The significance levels were $p<.05$ and $p<.01$, respectively, for the observed increases in approval for Total and Retaliation aggression. 
Table 5

Paired Samples T-tests - Comparison Group's Pre-/Post-test NOBAGS Scores

\begin{tabular}{|c|c|c|c|c|c|c|c|c|}
\hline \multirow{3}{*}{ NOBAGS Dimension } & \multicolumn{8}{|c|}{ Paired Differences } \\
\hline & \multirow[b]{2}{*}{ Mean } & \multirow{2}{*}{$\begin{array}{c}\text { Std. } \\
\text { Deviation }\end{array}$} & \multirow{2}{*}{$\begin{array}{l}\text { Std. } \\
\text { Error } \\
\text { Mean }\end{array}$} & \multicolumn{2}{|c|}{$\begin{array}{c}95 \% \text { Confidence Interval } \\
\text { of the Difference }\end{array}$} & \multirow[b]{2}{*}{$\mathbf{t}$} & \multirow[b]{2}{*}{ df } & \multirow{2}{*}{$\begin{array}{c}\text { Sig. } \\
(2- \\
\text { tailed) }\end{array}$} \\
\hline & & & & Lower & Upper & & & \\
\hline $\begin{array}{l}\text { Total Aggression Pre-test } \\
\text { Total Aggression Post-test }\end{array}$ & 3.15 & 10.94 & 1.28 & .59906 & 5.70231 & 2.461 & 72 & $.016^{*}$ \\
\hline $\begin{array}{l}\text { General Aggression Pre-test } \\
\text { General Aggression Post-test }\end{array}$ & .52 & 5.04 & .59 & -.65450 & 1.69560 & .883 & 72 & .380 \\
\hline \begin{tabular}{|l|} 
Retaliation Aggression Pre-test \\
Retaliation Aggression Post-test
\end{tabular} & 2.63 & 7.94 & .93 & .77722 & 4.48306 & 2.830 & 72 & $.006^{* *}$ \\
\hline
\end{tabular}

${ }^{*} p<.05 ; * * p<.01$

Regression analysis was used to assess the significance of the differences in outcomes between the Program and Comparison groups. Post-test scores for each NOBAGS scale and the IECA were regressed on the matched pre-test scores. The regression equation estimated was:

$$
\begin{aligned}
Y i=B_{0}+B_{1} X_{i} & +B_{2} Z_{i}+e_{i} \text { where: } \\
Y_{i} & =\text { Mean post-test score } \\
B_{0} & =\text { Expected value of } Y_{i} \text { when } X_{i} \text { and } Z_{i} \text { equal zero } \\
B_{1} & =\text { Mean difference for Program Group } \\
X_{i} & =\text { Mean score at pre-test } \\
B_{2} & =\text { Group effect } \\
Z_{i} & =\text { Dummy variable for Group }(0=\text { Comparison, } 1=\text { Program) } \\
e_{i} & \left.=\text { Residual (observed change in } Y_{i} \text { that is not explained by } X_{i} \text { and } Z_{i}\right)
\end{aligned}
$$

Total Aggression Table 6

NOBAGS Total Aggression-Regression Results, Coefficients (Standard Error)

\begin{tabular}{|l|l|l|l|}
\hline $\mathrm{Y}_{\mathrm{i}}=$ & 14.984 & $+.690 \mathrm{X}_{\mathrm{i}}-$ & $3.670 \mathrm{Z}_{1}$ \\
\hline & & $(.052)$ & $(1.259)$ \\
\hline & & $\mathrm{t}=$ & $-2.915^{* *}$ \\
\hline & $\mathrm{n}=201$ & $\mathrm{R}^{2}=.49$ \\
\hline${ }^{* *} p<.01$ &
\end{tabular}

The mean difference between the two group's pre- and post-test scores for Total Aggression was 3.67 points. The difference was determined to be significant at the $99 \%$ confidence level $(\mathrm{t}=-2.915, \mathrm{p}<.01)$.

\section{General Aggression}

The difference between the Program and Comparison group's pre- and post-test scores for General Aggression was very near the significant level $(t=-1.953, p=0.052)$. 
Table 7

NOBAGS General Aggression - Regression Results, Coefficients (Standard Error)

\begin{tabular}{|r|r|l|l|}
\hline $\mathrm{Y}_{\mathrm{i}=}$ & $4.297+$ & $.709 \mathrm{X}_{\mathrm{i}}-$ & $1.139 \mathrm{Z}_{1}$ \\
\hline & & $(.050)$ & $(.583)$ \\
\hline & & $\mathrm{t}=$ & -1.953 \\
\hline & & $\mathrm{R}^{2}=$ & .51 \\
& $\mathrm{n}=201$ & & \\
\hline
\end{tabular}

\section{Retaliation Aggression}

The mean difference in approval of Retaliation Aggression between pre- and post-test was approximately 2.62 points. The observed difference in outcomes between the Program and Comparison groups was significant $(\mathrm{t}=-2.931, p<.01)$.

Table 8

NOBAGS Retaliation Aggression-Regression Results, Coefficients (Standard Error)

\begin{tabular}{|l|r|r|l|}
\hline $\mathrm{Y}_{\mathrm{i}=}$ & $13.098+$ & \multicolumn{1}{c|}{$.585 \mathrm{X}_{\mathrm{i}}-$} & \multicolumn{1}{c|}{$2.615 \mathrm{Z}_{1}$} \\
\hline & & $(.058)$ & $(.892)$ \\
\hline & & $\mathrm{t}=$ & $-2.931 * *$ \\
\hline & $\mathrm{n}=201$ & $\mathrm{R}^{2}=$ & .36 \\
\hline &
\end{tabular}

The results for aggression suggested the Healing Species program may have arrested the progression toward more favorable beliefs about aggression that typically occurs among children as they accumulate more life experience. In their study of normative beliefs about aggression, Huesmann and Guerra found the greatest increases in approval of aggression and actual aggressive behavior occurred during the early elementary school years; and by fifth grade, normative beliefs about aggression are predictive of actual aggressive behavior in sixth grade (Huesmann \& Guerra, 1997).

\section{Results for the Index of Empathy}

Paired-samples T-tests were conducted to assess the direction and magnitude of change in the Program Group's pre- and post-test scores in the Index of Empathy for Children \& Adolescents (IECA). There was a significant decline between pre-test $(M=12.20, S D=3.65)$ and post-test $(M=11.06, S D=4.32)$ IECA scores $t(127)=3.62, p<.01$. The direction of the observed change was the opposite of the program's intended effect.

Outcomes were similar among the Comparison group students. Scores on the IECA declined between pre-test $(M=11.30, S D=3.178)$ and post-test $(M=10.99, S D=3.18)$, however the change was not significant $t(72)=.88, p=.380$. Regression analysis to compare IECA scores between the Program and Comparison groups revealed no significant difference in the post-test results for the two groups. 
Table 9

Index of Empathy - Regression Results, Coefficients (Standard Error)

\begin{tabular}{|l|r|l|l|}
\hline $\mathrm{Y}_{\mathrm{i}=}$ & $3.384+$ & $.673 \mathrm{X}_{\mathrm{i}}-$ & $.521 \mathrm{Z}_{1}$ \\
\hline & & $(.066)$ & $(.473)$ \\
\hline & & $\mathrm{t}=$ & -1.102 \\
\hline & $\mathrm{n}=201$ & $\mathrm{R}^{2}=$ & .35 \\
\hline
\end{tabular}

Pre-test to post-test comparisons of the entire study group's NOBAGS and IECA scores revealed negative correlations, indicating higher NOBAGS scores at pre-test were associated with lower post-test IECA scores. The negative correlation, together with the group's lower post-test score on the IECA, suggested the program may have been less effective among a small but influential subset of students with stronger favorable attitudes towards aggression.

Table 10

Pretest to Posttest Comparisons of NOBAGS and IECA Scores

\begin{tabular}{|l|c|c|c|}
\hline & Retaliation Aggression & General Aggression & Total Aggression \\
\hline IECA-Posttest & $-.196^{*}$ & $-.306^{* *}$ & $-.270^{* *}$ \\
\hline
\end{tabular}

*Pearson's correlation is significant at the $p<.05$ level (two-tailed)

**Pearson's correlation is significant at the $p<.01$ level (two-tailed)

\section{Discipline-related Outcomes}

To assess the relationship between beliefs and behavior, the study analyzed discipline data for the Program and Comparison groups for the fall and spring semesters. Analysis of the disciplinary data was complicated by the concurrency of the study period and the disciplinary periods under review. Data for the 4-weeks between the first day of school and the start of the Healing Species project showed students in the Program and Comparison groups began the school year incurring disciplinary referrals at similar rates. The number and rate of referrals for each group are summarized in Table 8. It is important to note the data in Table 8 precede the actual designation of the groups for the study. For the students who received disciplinary referrals before the start of the Healing Species project, the table reflects the group to which the students' classrooms were later assigned.

Table 11

Disciplinary Referrals Prior to Implementation of Healing Species Curriculum

\begin{tabular}{|l|c|}
\hline Study Group & Number (Rate) of Disciplinary Referrals \\
\hline Program $(n=128)$ & $15(11.72 \%)$ \\
\hline Comparison $(n=73)$ & $8(10.96 \%)$ \\
\hline \multicolumn{1}{|c|}{ Total $(\mathbf{n = 2 0 1 )}$} & $\mathbf{2 3 ( 1 1 . 4 4 \% )}$ \\
\hline
\end{tabular}

The project expected to see increases in the total number of disciplinary referrals from the start of Healing Species to the end of the school year. This expectation arose from a review of the schools' disciplinary practices, which showed the reporting of infractions increases as the school year progresses. Student behavior did not necessarily worsen, but tolerance of misbehavior decreased as behavioral expectations were steadily raised and consistently communicated over the course of the school year. Subsequent misbehavior resulted in graduated sanctions, which 
increased the number disciplinary referrals that were serious enough for entry into the school district's Schools Administrative Student Information (SASI) system.

The study hypothesized that the increase in referrals would be smaller for the Program group as the Healing Species lessons began to take effect. The regression equation estimated for disciplinary referrals was: $Y i=B_{0}+B_{1} Z_{i}+e_{i}$, where:

$$
\begin{aligned}
& Y_{i}=\text { Students' total number of disciplinary referrals for 2007-08 } \\
& B_{0}=\text { Expected value of } Y_{i} \text { when } Z_{i} \text { equals zero } \\
& B_{1}=\text { Group effect } \\
& Z_{i}=\text { Dummy variable for Group ( } 0=\text { Comparison, } 1=\text { Program) } \\
& e_{i}=\text { Residual (observed change in } Y_{i} \text { that is not explained by } Z_{i} \text { ) }
\end{aligned}
$$

\section{Regression Results for Disciplinary Referrals}

The study first estimated the effect of the Healing Species project on total disciplinary referrals for the Fall 2007 semester during which the project's curriculum was delivered to the Program group. The results reflected an average difference of nearly two fewer (1.6) referrals per student for students who received the Healing Species lessons.

Table 12

Fall Disciplinary Referrals - Regression Results, Coefficients (Standard Error)

\begin{tabular}{|r|r|l|}
\hline $\mathrm{Y}_{\mathrm{i}=}$ & $2.548-$ & $1.618 \mathrm{Z}_{1}$ \\
\hline & & $(.337)$ \\
\hline & $\mathrm{t}=$ & - \\
& & $4.807 * * *$ \\
\hline $\mathrm{n}=201$ & $\mathrm{R}^{2}=$ & .10 \\
\hline$* * * p<.001$
\end{tabular}

Next, the study examined total disciplinary referrals through the end of the spring semester, also marking the end of the school year, to assess retention of the observed program effect among the students who completed Healing Species in the fall (Table 13). By the end of the school year, the gap between the fall Program and Comparison groups widened, with the Program group students accumulating approximately 4 fewer referrals per student for the year.

Table 13

School Year 2007-08 Disciplinary Referrals - Regression Results, Coefficients (Standard Error)

\begin{tabular}{|r|r|l|}
\hline $\mathrm{Y}_{\mathrm{i}=}$ & $7.589-$ & $4.378 \mathrm{Z}_{1}$ \\
\hline & & $(.915)$ \\
\hline & $\mathrm{t}=$ & $-4.782 * * *$ \\
\hline $\mathrm{n}=201$ & $\mathrm{R}^{2}=$ & .10 \\
\hline$* * * p<.001$
\end{tabular}

A primary goal of the Healing Species lessons is to teach nonviolent strategies for conflict resolution. Therefore, the study's analysis of disciplinary data included separate analyses of referrals for aggressive and violent behaviors. Discipline codes included in these categories were: Hitting Others, Fighting, Simple Assault, Threat to Student, Intimidation, and Threat to Staff. The school district's discipline codes include other acts of violence such as Aggravated Assault and Possessing a Weapon, however the study was limited only to actual disciplinary infractions committed during the 2007-08 school year. As shown in Table 14, the results for the fall semester suggested a weak (R2 $=.05)$, but significant, program effect: 
Table 14

Fall Semester Aggressive \& Violent Behaviors - Regression Results, Coefficients

(Standard Error)

\begin{tabular}{|r|r|l|}
\hline $\mathrm{Y}_{\mathrm{i}}$ & $.411-$ & $.270 \mathrm{Z}_{1}$ \\
\hline & & $(.086)$ \\
\hline & $\mathrm{t}=$ & $-3.127^{* *}$ \\
\hline $\mathrm{n}=201$ & $\mathrm{R}^{2}=$ & .05 \\
\hline$* * * p<.01$ &
\end{tabular}

Though not as robust as anticipated $(R 2=.08)$, the program effect appeared to have persisted through the end of the school year, as reflected in the regression results shown in Table 15. For the 2007-08 school year, the Program group received .57 fewer referrals per student for aggressive or violent behavior.

Table 15

School Year 2007-08 Aggressive \& Violent Behaviors - Regression Results, Coefficients (Standard Error)

\begin{tabular}{|r|r|l|}
\hline $\mathrm{Y}_{\mathrm{i}=}$ & $.945-$ & $.570 \mathrm{Z}_{1}$ \\
\hline & & $(.142)$ \\
\hline & $\mathrm{t}=$ & $-4.024 * * *$ \\
\hline $\mathrm{n}=201$ & $\mathrm{R}^{2}=$ & .08 \\
\hline$* * * p<.001$ &
\end{tabular}

\section{Discussion}

The results for students' normative beliefs about aggression were consistent across all three measures. For Retaliation, General, and Total aggression, post-test scores on approval of aggression declined as theorized. The results for Total and Retaliation aggression, combined with the students' positive behavioral outcomes, suggest it may be reasonable to conclude the results for General Aggression were indeed significant, and the slightly higher $p$ value may have been attributable to random error.

Findings regarding students' cognitive expression of empathy were inconsistent with social development theory, which has found higher levels of empathy are typically correlated with lower levels of aggression. In this study, students exhibited improved behavior despite observed deterioration of students' cognitive standards regarding empathic behaviors.

Completing the Healing Species curriculum did not appear to decrease the Program Group's approval of aggression; however, increased normative beliefs approving of aggression were evident for the Comparison Group. This suggested Healing Species' may have helped prevent the Program Group's pre-intervention normative beliefs from deteriorating. The relative stability of the Program Group's attitudes toward aggression was consistent with the student discipline measures, which showed improved overall behavior and specific reductions in the incidences of violence and aggression (Figure 1). 
Figure 1

Change in Rate of Disciplinary Referrals from Dec 2007 to May 2008

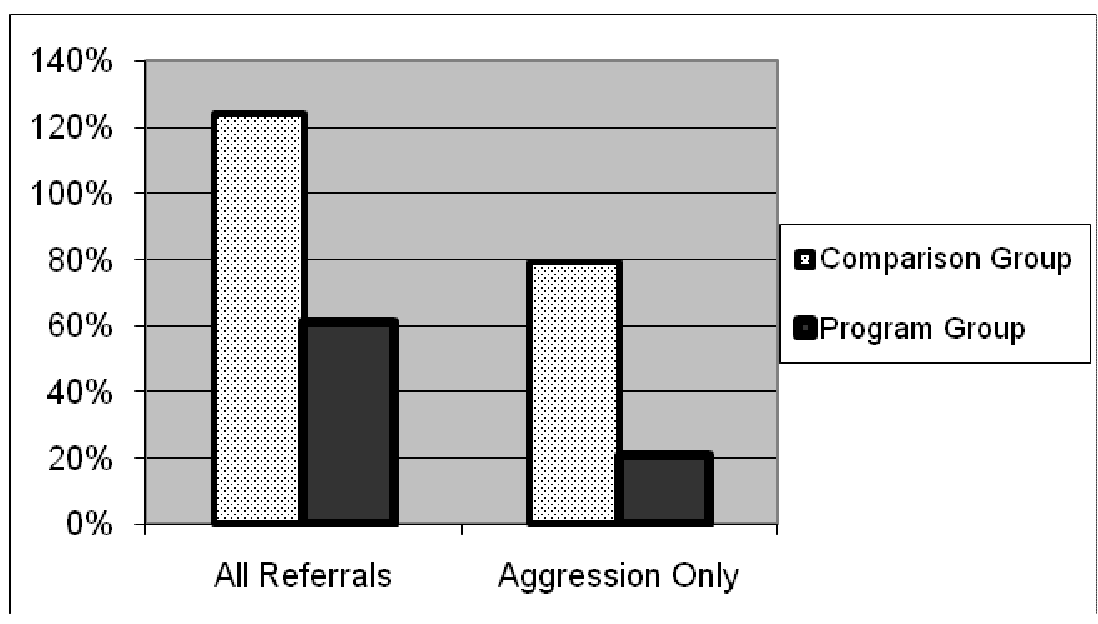

The demographics of the study participants were an uncertain factor in the study's outcome hypotheses. The study population was $60 \%$ female; among these, $72 \%$ were Black or African American. Based on a body of research showing females tend to be more empathic than males, the preponderance of girls $(60 \%)$ in this study appeared to support our hypothesized increase in empathy. At the same time, research has also documented higher levels of normative beliefs about aggression among children living in poor, urban neighborhoods, a description that characterized $68 \%$ of our study population (Anderson, 1990; Fingerhut \& Kleinman, 1990). The final study results were consistent with earlier findings of smaller differences in scores on the Index of Empathy (IECA) for African American students, despite the female majority in the study population (Sprinkle, 2008).

To the extent aggressive or violent behavior represents attempts to exercise power, the program's apparent success in reducing violent and aggressive behaviors may be explained by the curriculum's focus on practical strategies for asserting personal power without resorting to aggression or violence. Students were encouraged to recognize and take responsibility for their feelings by:

1) finding someone they could talk to;

2) grieving hurtful events; and

3) healing hurt feelings by showing love to an animal, another person, or oneself.

Where students may have believed aggressive or violent behavior offered some influence, however limited, over their world, the Healing Species lessons modeled alternative ways to exert power, e.g., setting and achieving goals, caring for the more vulnerable, and acting from awareness of one's self-worth. Lessons were reinforced by the presence of the rescued dog and the facilitator's recounting of the dog's story to illustrate resilience and demonstrate that positively changing someone's world - even that of an abused or abandoned animal-was within nearly everyone's personal power.

Overall, the disparities between the students' observed behavior and their cognitive beliefs may have been due to incongruity between the curriculum's intended and actual cognitive targets. 
Behavioral results were encouraging, but additional study is needed to determine how the Healing Species' program elements effect behavioral change.

\section{Conclusion}

The evaluation's implications for increased school safety and effective classroom management should be of interest to anyone with a stake in ensuring that schools provide safe, nurturing environments where learning can take place. For teachers, school administrators, and parents, practical considerations of the observed changes on student behavior included:

- Of the 63 students who received no disciplinary referrals for the school year, 45 (nearly $75 \%$ ) were in the Program group.

- Program group students accounted for 49 (83\%) of the 59 students who received 3 referrals or fewer for the school year.

The Healing Species program appeared to facilitate positive changes in student behavior, though the program's impact on beliefs that were hypothesized to drive behavior was less certain. Further study is indicated to determine which cognitive factors that influence behavior are impacted by Healing Species and how those factors may be incorporated to strengthen the program's benefits to diverse study populations.

\section{References}

Anderson, E.J. (1990). Streetwise: Race, class, and change in an urban community. Chicago: University of Chicago Press.

Berkowitz, L. (1993). Pain and Aggression: Some Findings and Implications. Motivation and Emotion, 17:3, 277-293.

Bryant, B.K. (1982). An Index of Empathy for Children and Adolescents. Child Development, 53:2, 413-425, 1982.

Embry, D.D. (2004). Community-based Prevention Using Simple, Low-Cost, Evidence-Based Kernels and Behavior Vaccines. Journal of Community Psychology, 32:5, 575-591.

Embry, D.D. (1996). Reasons for hope: creating a climate for change and resiliency. In W.L. Reed (ed.) Violence and Childhood Trauma: Understanding and Responding to the Effects of Violence on Young Children. Cleveland, $\mathrm{OH}$ : Urban Child Research Center.

Embry, D.D., \& Flannery, D.J. (1999). Two sides of the coin: Multi-level prevention and intervention to reduce youth violent behavior. A chapter for D.J. Flannery and C. Ronald Huff (eds.), Youth Violence: Prevention, Intervention and Social Policy. Washington, DC: American Psychiatric Press.

Evans, G.W., \& Schamberg, M.A. (2009). Childhood poverty, chronic stress, and adult working memory. Proceedings of the National Academy of Sciences of the United States of America (PNAS), published online, doi: 10.1073/pnas.0811910106.

Farah, M.J., et al. (2006). Childhood poverty: Specific associations with neurocognitive development. Brain Research 110:166-174. 
Fingerhut, L.A., \& Kleinman, J.C. (1990). The international and interstate comparisons of homicide among young males. Journal of the American Medical Association, 263:24, 32923296.

Flynn, C.P. (1999). Animal Abuse in Childhood and Later Support for Interpersonal Violence in Families. Society and Animals 7:2,161-171.

Haberman, M. (1994). Gentle Teaching in a Violent Society. educational HORIZONS 72:3, 238248.

"Helping Traumatized Children: A Brief Overview for Caregivers," by Bruce Perry, M.d., Ph.D., Child Trauma Academy, August 1999.

Huesmann, L., Rowell, \& Guerra, N.G. (1997). Children's Normative Beliefs About Aggression and Aggressive Behavior. The Journal of Personality and Social Psychology 72:2, 408-419.

Huesmann, L., Rowell, Guerra, N.G., Miller, L., \& Zelli, A. (1989). The Normative Beliefs about Aggression Scale. Chicago: University of Illinois

Karr-Morse, R., \& Wiley, M. (1997). Ghosts from the Nursery: Tracing the Roots of Violence. New York: Atlantic Monthly Press.

Kellert, S.R., \& Felthous, A.R. (1985). Childhood Cruelty toward Animals Among Criminals and Noncriminals. Human Relations 38:12, 1113-1129.

Miller, K.S., \& Knutson, J.F. (1997). Reports of Severe Physical Punishment and Exposure to Animal Cruelty by Inmates Convicted of Felonies and by University Students. Child Abuse and Neglect: The International Journal 21: 1, 59-82.

Patterson, G.R., Debaryshe, B.D., \& Ramsey, E. (1989). A developmental perspective on antisocial behavior. American Psychologist, 44:2, 329-335.

Perry, B.D. (2000). Traumatized Children: How childhood trauma influences brain development. The Journal of the California Alliance for the Mentally III 11:1, 48-51.

Sprinkle, J.E. (2008). Animals, Empathy, and Violence: Can Animals Be Used to Convey Principles of Prosocial Behavior to Children? Youth Violence and Juvenile Justice 6:1, 47-58.

U.S. Census Bureau. (2005-2007). American Community Survey 3-year Estimates. Retrieved from http://factfinder.census.gov.

U.S. Census Bureau. (2009). State and County QuickFacts. Retrieved from http://quickfacts.census.gov.

(C) Copyright of Journal of Youth Development Bridging Research and Practice. Content may not be copied or emailed to multiple sites or posted to a listserv without copyright holder's express written permission. However, users may print, download or email articles for individual use. 